\title{
Penempatan Tanaman Upakara sebagi Elemen Lunak Taman Pekarangan Rumah Ditinjau dari Aspek Filosofi Budaya Bali di Kecamatan Payangan, Kabupaten Gianyar, Provinsi Bali
}

\section{DESAK PUTU LOLA AMBARANI ${ }^{1}$, A.A. GEDE DALEM SUDARSANA ${ }^{2 *}$, SANG MADE SARWADANA²}

1. Program Studi Agroekoteknologi, Fakultas Pertanian, Universitas Udayana, Denpasar, 80225 Indonesia

2. Program Studi Arsitektur Pertamanan, Fakultas Pertanian, Universitas Udayana Denpasar, 80225 Indonesia

*E-mail: agungdalems@gmail.com

\section{ABSTRACT \\ The Placement of Ritual Plants as Soft Elements of Garden Reviewed from Aspect of Balinese Culture Philosophy in District of Payangan, Gianyar Regency, Province of Bali}

Hindus community in Bali always held a religious rituals throughout the year. Most of the ritual elements are descended from plants which are well known as "ritual plants". Traditional garden of Bali should use ritual plants as a landscaping plant. Objectives of this research were to determine ritual plant as a soft elements of garden located in district of Payangan, Gianyar regency, province of Bali and to review the placement ritual plants from aspects of Balinese philosophy. Data were collected from three villages in Payangan throught field survey. Results showed that there were as many as 48 samples of house were surveyed with 80 species of ritual plants found as it used as elements of garden in district of Payangan. The placement of ritual plants were appropriate to the philosophy concepts of Balinese culture which were Tri Mandala and Asta Dala. Unfortunately, these concept were not implemented by the people in Payangan district because of the lack of knowledge.

Keywords: Balinese philosophy, Payangan district, plant placement, ritual plants

\section{Pendahuluan}

Pulau Bali dikenal sebagai Pulau Seribu Pura dengan mayoritas penduduk beragama Hindu yang tidak pernah lepas dari ritual keagamaan yang dilakukan hampir sepanjang tahun. Pelaksanaan ritual keagamaan di Bali membutuhkan berbagai jenis tumbuhan yang digunakan sebagai sarana kelengkapan upakara. Keberadaan tanaman upakara harus tetap lestari selama agama Hindu masih eksis di Bali. Menggunakan tanaman upakara 
sebagai elemen lunak taman pekarangan rumah selain untuk pemenuhan arsitektural, estetika, dan fungsional, juga dapat dimanfaatkan untuk keperluan upakara, sehingga tanaman yang digunakan dalam pertamanan tradisional Bali dapat memiliki fungsi ganda, di samping itu pemanfaatan tanaman upakara sebagai elemen taman juga merupakan salah satu upaya pelestarian tanaman upakara.

Menurut Prajoko (2012) taman di Bali bukan saja melibatkan arsitektural, fungsional, estetika, akan tetapi juga melibatkan filosofi budaya Bali di setiap penempatan komponen pertamanannya, sehingga terpola sedemikian rupa, baku dan khas untuk setiap komponen yang ada. Kekhasan dan keunikan pertamanan tradisonal Bali sebagai kearifan lokal, sangat berpotensi dikembangkan sebagai keunggulan lokal di bidang desain pertamanan. Kenyataannya belum banyak masyarakat yang menata pertamanannya sesuai dengan filosofi budaya Bali yang terdiri dari filosofi Tri Mandala dan Asta Dala. Payangan merupakan salah satu kecamatan yang terdapat di Kabupaten Gianyar yang 99,7\% penduduknya beragama Hindu dan menggunakan tanaman upakara sebagai elemen lunak taman pekarangan rumah. Oleh karena itu, penulis merasa perlu untuk melakukan penelitian mengenai penempatan tanaman upakara sebagai elemen lunak taman pekarangan rumah ditinjau dari aspek filosofi budaya Bali di Kecamatan Payangan, Kabupaten Gianyar, Provinsi Bali.

Rumusan masalah penelitian ini atara lain 1) Tanaman upakara apa saja yang dimanfaatkan sebagai elemen lunak taman pekarangan rumah di Kecamatan Payangan, Kabupaten Gianyar, Provinsi Bali? 2) Bagaimana penempatan tanaman upakara sebagai elemen lunak taman pekarangan rumah ditinjau dari aspek filosofi budaya Bali di Kecamatan Payangan, Kabupaten Gianyar, Provinsi Bali?, sedangkan tujuan penelitian meliputi inventarisasi tanaman upakara yang dimanfaatkan sebagai elemen lunak taman pekarangan rumah di Kecamatan Payangan, Kabupaten Gianyar, Provinsi Bali dan mengetahui penempatan tanaman upakara sebagai elemen lunak taman pekarangan rumah ditinjau dari aspek filosofi budaya Bali di Kecamatan Payangan, Kabupaten Gianyar, Provinsi Bali. Lebih lanjut penelitian ini diharapkan akan memberikan manfaat bagi pemerintah yaitu sebagai bahan acuan dan pertimbangan untuk mengambil suatu kebijakan di dalam penataan taman pekarangan rumah yang sesuai filosofi budaya Bali. Berikutnya adalah manfaat bagi masyarakat luas yaitu sebagai acuan untuk menata taman pekarangan rumah sesuai filosofi budaya Bali dan terakhir adalah manfaat bagi peneliti yaitu dapat mengetahui tanaman upakara yang digunakan sebagai elemen lunak taman pekarangan rumah di Kecamatan Payangan dan memahami penempatan tanaman ditinjau dari aspek filosofi budaya Bali.

\section{Metode}

\subsection{Waktu dan Tempat}

Penelitian dilaksanakan di Kecamatan Payangan, Kabupaten Gianyar, Provinsi Bali. Penelitan berlangsung selama tiga bulan yang dimulai dari bulan Maret sampai dengan Mei 2016. 


\subsection{Alat}

Alat yang digunakan dalam penelitian ini ialah berupa kamera digital, serta komputer untuk mengolah data dengan menggunakan software Microsoft Office Word, Microsoft Office Excel dan lembar kuesioner.

\subsection{Populasi dan Sampel}

Populasi dalam penelitian adalah seluruh wilayah di Kecamatan Payangan. Teknik pengambilan sampel dalam penelitian ini adalah dengan menggunakan teknik purposive sampling yaitu, pengambilan sampel secara sengaja sesuai dengan persyaratan sampel yang diperlukan (Ulwan, 2014). Jumlah sampel yang digunakan ialah sebanyak 48 rumah yang dianggap dapat mewakili rumah penduduk yang lainnya yang memiliki kriteria sebagai berikut: rumah tradisional Bali di Desa Bukian, Desa Melinggih dan Desa Kerta yang menggunakan tanaman upakara sebagai elemen lunak taman pekarangan rumah.

\subsection{Metode Penelitian}

Metode penelitian yang digunakan dalam penelitian ini adalah metode survei dengan teknik observasi, wawancara dan kuesioner.

a. Observasi

Observasi dilakukan dengan mengamati secara langsung untuk mengumpulkan data dan mendatangi langsung rumah responden serta mendokumentasikan hal-hal yang dianggap perlu untuk menunjang penelitian ini. Data yang diamati terkait tanaman upakara yang digunakan sebagai elemen lunak taman pekarangan rumah di masing-masing rumah responden pada bagian Utama Mandala atau merajan, Madya Mandala atau natah dan Nista Mandala atau telajakan, serta penempatan tanaman tersebut.

b. Wawancara

Wawancara merupakan teknik pengumpulan data yang dilakukan dengan mengadakan tanya jawab secara langsung kepada informan pangkal yaitu kepala desa dan informan kunci yaitu kepala keluarga dari setiap rumah sampel yang dapat memeberikan informasi secara baik dan jelas, serta informan pendukung yaitu tokoh-tokoh masyarakat yang berkompeten dalam bidang tanaman upakara. Pertanyaan yang diajukan kepada responden terkait dengan penempatan tanaman upakara sebagai elemen lunak taman pekarangan rumah.

c. Kuesioner

Kuesioner dilakukan dengan memberikan angket atau daftar pertanyaan kepada responden. Jenis kuesioner yang digunakan dalam penelitian ini adalah kuesioner tertutup yaitu multiple choice yang terdiri dari lima pilihan jawaban. Pertanyaan pada kusioner terkait dengan pandangan masyarakat terhadap penggunaan tanaman upakara sebagai elemen lunak taman pekarangan rumah.

\subsection{Analisis Data}

Data yang didapat diolah secara deskriptif yang artinya memaparkan berbagai informasi dan data yang diperoleh, sehingga menjadi kesatuan yang utuh. Menurut 
Kountur (2004), penelitian deskriptif adalah jenis penelitian yang memberikan gambaran atau uraian atas suatu keadaan sejelas mungkin tanpa ada perlakuan terhadap obyek yang diteliti.

\section{Hasil dan Pembahasan}

\subsection{Hasil Inventarisasi Tanaman Upakara yang Digunakan sebagai Elemen Lunak Taman Pekarangan Rumah di Kecamatan Payangan}

Berdasarkan penelitian yang dilakukan pada 48 sampel rumah di Kecamatan Payangan didapatkan 80 jenis tanaman upakara yang digunakan sebagai elemen lunak taman pekarangan rumah.

Tabel 1. Tanaman Upakara yang Digunakan sebagai Elemen Lunak Taman Pekarangan Rumah di Kecamatan Payangan

\begin{tabular}{|c|c|c|c|c|c|c|}
\hline \multirow{2}{*}{ No } & \multirow{2}{*}{$\begin{array}{c}\text { Jenis } \\
\text { Tanaman }\end{array}$} & \multirow{2}{*}{ Nama Tanaman } & \multicolumn{3}{|c|}{ Peletakan } & \multirow{2}{*}{ Jumlah } \\
\hline & & & $U M$ & MM & NM & \\
\hline 1 & Daun & Andong (Cordyline fruticosa) & 181 & 281 & 176 & 638 \\
\hline 2 & & Beringin (Ficus benjamina) & 0 & 11 & 0 & 11 \\
\hline 3 & & Brotowali (Tinospora crispa) & 0 & 3 & 0 & 3 \\
\hline 4 & & Bunut bulu & 0 & 3 & 0 & 3 \\
\hline 5 & & Dadap (Erytherina variegata) & 19 & 8 & 1 & 28 \\
\hline 6 & & Daun Wungu (Graptophyllum pictum) & 0 & 9 & 3 & 12 \\
\hline 7 & & Delem Jawa (Pogostemon hortensis) & 0 & 2 & 1 & 3 \\
\hline 8 & & Gelagah (Saccharum spontaneum) & 0 & 2 & 0 & 2 \\
\hline 9 & & Karuk (Chavica sarmentosa) & 0 & 2 & 0 & 2 \\
\hline 10 & & Katuk (Sauropus androgynus) & 1 & 9 & 2 & 12 \\
\hline 11 & & Kumbang & 0 & 1 & 1 & 2 \\
\hline 12 & & Kelor (Moringa oleifera) & 0 & 8 & 1 & 9 \\
\hline 13 & & Kemukus (Piper cubeba) & 2 & 1 & 1 & 4 \\
\hline 14 & & Nagasari (Mesua ferrea) & 4 & 1 & 0 & 5 \\
\hline 15 & & Paku Aji (Alsophila glauca) & 0 & 3 & 3 & 6 \\
\hline 16 & & Paku Pipid(Nephrolepis biserrata) & 4 & 112 & 0 & 116 \\
\hline 17 & & Pandan Duri (Pandanus furcatus) & 2 & 15 & 1 & 18 \\
\hline 18 & & $\begin{array}{c}\text { Pandan Wangi (Pandanus } \\
\text { amaryllifolius) }\end{array}$ & 173 & 35 & 10 & 218 \\
\hline 19 & & Pulai (Alstona scholaris) & 0 & 4 & 1 & 5 \\
\hline 20 & & Puring (Codiaeum variegatum) & 27 & 100 & 38 & 165 \\
\hline 21 & & Salam (Eugenia polyantha) & 0 & 5 & 0 & 5 \\
\hline 22 & & Seligi (Phyllanthus buxifolius) & 1 & 10 & 3 & 14 \\
\hline 23 & & Senduduk (Melastoma malabathikum) & 0 & 2 & 2 & 4 \\
\hline 24 & & Sente (Alocasia macrorrhiza) & 0 & 10 & 0 & 10 \\
\hline
\end{tabular}




\begin{tabular}{|c|c|c|c|c|c|c|}
\hline \multirow{2}{*}{ No } & \multirow{2}{*}{$\begin{array}{c}\text { Jenis } \\
\text { Tanaman }\end{array}$} & \multirow{2}{*}{ Nama Tanaman } & \multicolumn{3}{|c|}{ Peletakan } & \multirow{2}{*}{ Jumlah } \\
\hline & & & UM & $M M$ & $N M$ & \\
\hline 25 & & $\begin{array}{c}\text { Simbar Menjangan (Platycerium } \\
\text { bifurcatum) }\end{array}$ & 1 & 109 & 2 & 112 \\
\hline 26 & & Sirih (Piper betle) & 1 & 14 & 1 & 16 \\
\hline 27 & & Suji (Pleomele angustifolia) & 2 & 15 & 0 & 17 \\
\hline 28 & & Uduh (Caryota mitis) & 0 & 1 & 1 & 2 \\
\hline 29 & & Walisongo (Schefflera grandiflora) & 0 & 13 & 11 & 24 \\
\hline 30 & & Waru (Hibiscus tiliaceus) & 0 & 1 & 0 & 1 \\
\hline 31 & Bunga & Alamanda (Allamanda cathartica) & 9 & 5 & 2 & 16 \\
\hline 32 & & Bugenvil (Bougainvillea spectabilis) & 21 & 61 & 1 & 83 \\
\hline 33 & & Cempaka (Michelia champaka) & 0 & 15 & 3 & 18 \\
\hline 34 & & Gemitir (Tagetes erecta) & 0 & 27 & 0 & 27 \\
\hline 35 & & Hortensia (Hydrangea macrophylla) & 30 & 49 & 0 & 79 \\
\hline 36 & & Kacapiring (Gardenia augusta) & 2 & 13 & 2 & 17 \\
\hline 37 & & Kamajaya & 3 & 1 & 0 & 4 \\
\hline 38 & & Kamboja (Plumeria acuminata) & 63 & 283 & 33 & 379 \\
\hline 39 & & $\begin{array}{c}\text { Kembang Merak (Caesalpinia } \\
\text { pulcherrima) }\end{array}$ & 1 & 1 & 0 & 2 \\
\hline 40 & & $\begin{array}{c}\text { Kembang Sepatu (Hibiscus rosa- } \\
\text { sinensis) }\end{array}$ & 9 & 27 & 0 & 36 \\
\hline 41 & & Kenanga (Canangium odoratum) & 16 & 17 & 0 & 33 \\
\hline 42 & & Mawar (Rosa sp.) & 10 & 58 & 3 & 71 \\
\hline 43 & & Melati (Jasminum pubescens) & 0 & 2 & 1 & 3 \\
\hline 44 & & Nusa Indah (Mussaenda pubescens) & 2 & 3 & 0 & 5 \\
\hline 45 & & Pacar Air (Impatiens balsamina) & 3 & 71 & 1 & 75 \\
\hline 46 & & Pacar Cina (Aglaia odorata) & 0 & 5 & 0 & 5 \\
\hline 47 & & Ratna (Gomphrena globosa) & 10 & 48 & 0 & 58 \\
\hline 48 & & Selasih (Ocimum bacilicum) & 0 & 26 & 0 & 26 \\
\hline 49 & & Soka (Ixora paludosa) & 7 & 13 & 2 & 22 \\
\hline 50 & & Soko Asti & 0 & 1 & 0 & 1 \\
\hline 51 & & Sudamala (Artemisia vulgaris) & 0 & 1 & 0 & 1 \\
\hline 52 & & Telang (Clitoria ternatae) & 2 & 10 & 2 & 14 \\
\hline 53 & & Teratai (Nymphaea lotus) & 0 & 21 & 0 & 21 \\
\hline 54 & & Widuri (Calotropis gigantean) & 1 & 6 & 0 & 7 \\
\hline 55 & & Wijaya Kusuma (Pisonia silvestris) & 2 & 0 & 0 & 2 \\
\hline 56 & Buah & Belimbing (Averrhoa carambola) & 2 & 7 & 0 & 9 \\
\hline 57 & & Buah Naga (Hylocereus undatus) & 0 & 29 & 2 & 31 \\
\hline 58 & & Buni (Antidesma bunius) & 0 & 1 & 0 & 1 \\
\hline 59 & & Cabai (Capsicum annuum) & 0 & 4 & 0 & 4 \\
\hline
\end{tabular}




\begin{tabular}{|c|c|c|c|c|c|c|}
\hline \multirow{2}{*}{ No } & \multirow{2}{*}{$\begin{array}{c}\text { Jenis } \\
\text { Tanaman }\end{array}$} & \multirow{2}{*}{ Nama Tanaman } & \multicolumn{3}{|c|}{ Peletakan } & \multirow{2}{*}{ Jumlah } \\
\hline & & & $U M$ & $M M$ & $N M$ & \\
\hline 60 & & Delima (Punica granatum) & 4 & 3 & 0 & 7 \\
\hline 61 & & Gegirang (Leea angulata) & 0 & 1 & 0 & 1 \\
\hline 62 & & Jambu Air (Eugenia aquena) & 0 & 4 & 1 & 5 \\
\hline 63 & & Jambu Biji (Psidium guajava) & 0 & 22 & 3 & 25 \\
\hline 64 & & Jeruk (Citrus sp.) & 8 & 21 & 10 & 39 \\
\hline 65 & & Kapas (Gossypium arboreum) & 0 & 0 & 1 & 1 \\
\hline 66 & & Leci (Litchi chinensis) & 0 & 0 & 2 & 2 \\
\hline 67 & & Mangga (Mangifera indica) & 0 & 7 & 2 & 9 \\
\hline 68 & & Manggis (Gracinia mangostana) & 0 & 0 & 5 & 5 \\
\hline 69 & & Mengkudu (Morinda citrifolia) & 0 & 1 & 2 & 3 \\
\hline 70 & & Nyuh Bulan (Cocos nucifera "Bulan") & 0 & 0 & 2 & 2 \\
\hline 71 & & $\begin{array}{l}\text { Nyuh Gading (Cocos nucifera } \\
\text { "Gading") }\end{array}$ & 1 & 1 & 6 & 8 \\
\hline 72 & & Rambutan (Nephelium lappaceum) & 0 & 2 & 0 & 2 \\
\hline 73 & & Terong Bola (Solanum mamosum) & 0 & 3 & 0 & 3 \\
\hline 74 & Umbi & Dlingo (Acorus calamus) & 0 & 5 & 0 & 5 \\
\hline 75 & & Jahe (Zingiber oficinale) & 0 & 4 & 1 & 5 \\
\hline 76 & & Kunyit (Curcuma longa) & 0 & 22 & 3 & 25 \\
\hline 77 & & Temu Agung (Curcuma aeruginosa) & 0 & 3 & 0 & 3 \\
\hline 78 & & Temu Gongseng & 0 & 1 & 0 & 1 \\
\hline 79 & & Temu Tis (Curcuma purpurascens) & 0 & 3 & 2 & 5 \\
\hline \multirow[t]{3}{*}{80} & Batang & Tebu (Saccharum officinarunm) & 34 & 15 & 0 & 49 \\
\hline & & Jumlah & 658 & 1713 & 351 & 2722 \\
\hline & & Persentase (\%) & 24 & 63 & 13 & 100 \\
\hline
\end{tabular}

Keterangan: UM (Utama Mandala), MM (Madya Mandala), NM (Nista Mandala)

\subsection{Pembahasan}

3.1.1 Tanaman Upakara sebagai Elemen Lunak Taman Pekarangan Rumah di Kecamatan Payangan

Penelitian yang dilakukan pada 48 sampel rumah menunjukkan sebanyak 80 jenis tanaman upakara (Tabel 1) digunakan sebagai elemen lunak taman pekarangan rumah di Kecamatan Payangan dengan total mencapai 2722 tanaman. Tanaman upakara yang ditanam tersebar di tiga area yaitu Utama Mandala, Madya Mandala dan Nista Mandala. Sebanyak 24\% dari total populasi tanaman ditanam di Utama Mandala, 63\% di Madya Mandala dan 13\% ditanam di Nista Mandala. Sebagian besar tanaman ditanam pada areal Madya Mandala karena merupakan tempat yang paling banyak untuk melakukan aktivitas, selain itu dengan lebih banyak menanam pada areal Madya Mandala dianggap akan lebih mudah mencari ketika memerlukan tanaman upakara. Areal Utama Mandala tidak terlalu banyak ditanami tanaman karena sebagian besar ruang kosong di areal Utama Mandala dilapisi perkerasan. Nista Mandala yang diamati pada penelitian ini hanya pada bagian 
telajakan. Telajakan merupakan areal yang paling sedikit ditanami tanaman karena ruang yang tersedia tidak terlalu luas.

Tanaman berdasarkan fungsi yang digunakan dalam upakara dikelompokkan menjadi tanaman yang dimanfaatkan daunnya sebanyak 30 jenis, tanaman yang dimanfaatkan bunganya sebanyak 25 jenis, tanaman yang dimanfaatkan buahnya sebanyak 18 jenis, tanaman yang dimanfaatkan umbinya sebanyak enam jenis dan tanaman yang dimanfaatkan batangnya sebanyak satu jenis. Tanaman yang dimanfaatkan daun, bunga dan buahnya merupakan tanaman yang paling banyak ditanam karena paling sering digunakan untuk pembuatan upakara. Pernyataan tersebut sesuai dengan kitab Bhagavadgita Bab IX sloka 26 yang menyebutkan bahwa sarana pokok yang wajib dipakai dasar untuk membuat persembahan terdiri dari pattram (daun-daunan), puspam (bunga), phalam (buah-buahan) dan toyam (air suci atau tirtha) (Srimad, 2006).

Hasil survei menunjukkan terdapat tanaman beringin dan pulai yang digunakan sebagai elemen lunak taman pekarangan rumah di Kecamatan Payangan. Tanaman beringin dan pulai kurang baik jika digunakan sebagai elemen lunak taman pekarangan rumah karena diyakini tanaman tersebut dihuni oleh makhluk halus serta dapat menyebabkan sakit (pamalinan). Sesuai dengan pendapat Putra (2009) yang menyebutkan terdapat pohon-pohon yang ditempati oleh makhluk halus seperti pohon beringin, kepuh, pulai, ancak, dan sebagainya.

\subsubsection{Penempatan Tanaman Upakara sebagai Elemen Lunak Taman Pekarangan} Rumah Ditinjau dari Aspek Filosofi Budaya Bali di Kecamatan Payangan

Hasil wawancara menunjukkan sebanyak $77 \%$ masyarakat meyatakan setuju apabila taman yang sesuai dengan filosofi budaya Bali dikembangkan di Kecamatan Payangan, namun $79 \%$ masyarakat menyatakan tidak mengetahui penempatan tanaman sesuai filosofi Budaya Bali. Pemerintahan desa di Kecamatan Payangan belum pernah mengadakan penyuluhan pengenai penempatan tanaman, sehingga perlu dilakukannya penyuluhan kepada masyarakat Kecamatan Payangan agar masyarakat mengetahui penempatan tanaman sesuai filosofi budaya Bali.

\section{a. Tri Mandala}

Berdasarkan survei yang dilakukan pada 48 rumah sampel menunjukkan bahwa masyarakat Kecamatan Payangan dalam menata taman pekarangan rumahnya belum sesuai filosofi Tri Mandala, namun secara tidak sengaja sebanyak 35\% penempatan tanaman upakara sudah sesuai dengan filosofi Tri Mandala. Menurut Sardiana dkk. (2012) Utama Mandala merupakan ruang yang bernilai suci, sehingga konsep taman diutamakan tanaman yang bagian bunga, daun, dan batangnya berfungsi sebagai sarana upakara. Madya Madala merupakan bagian pekarangan yang cocok ditanami jenis tanaman bunga habitus pohon dan tanaman buah. Nista Mandala merupakan areal telajakan, tanaman dipilih yang memiliki fungsi sebagai tanaman tabir. 


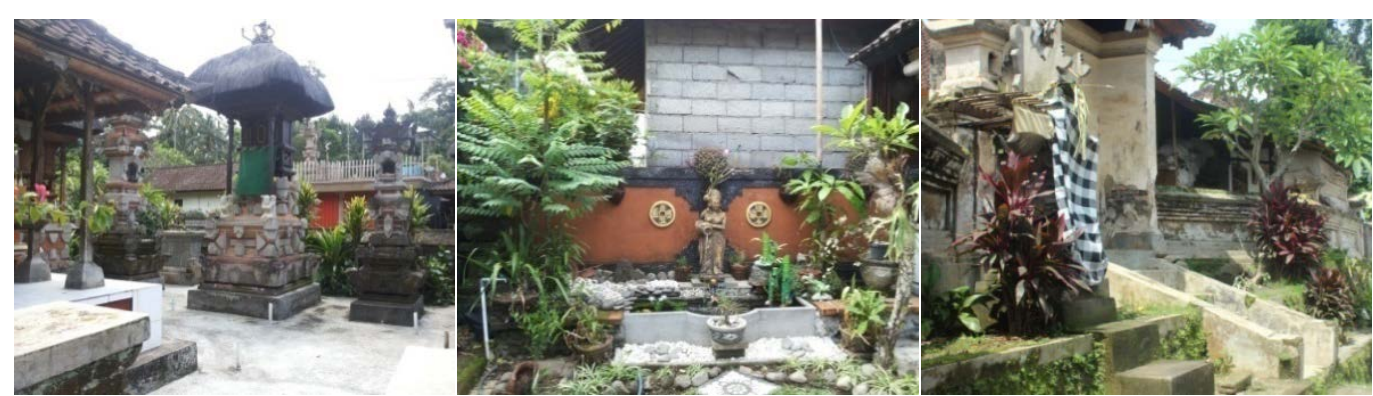

(a)

(b)

(c)

Gambar 1. Penempatan Tanaman Upakara sebagai Elemen Lunak Taman Pekarangan Rumah di Kecamatan Payangan

(a) Utama Mandala (b) Madya Mandala (c) Nista Mandala

\section{b. Asta Dala}

Berdasarkan hasil survei yang dilakukan pada 48 sampel rumah dapat diketahui bahwa masyarakat Kecamatan Payangan dalam menata taman pekarangan rumahnya belum sesuai dengan konsep Asta Dala. Masyarakat kurang memahami penempatan tanaman sesuai konsep Asta Dala, walaupun dalam pembuatan beberapa upakara menggunakan konsep yang sama, namun masyarakat tidak mengetahui bahwa konsep Asta Dala dapat digunakan dalam menata taman. Penempatan atau penanaman tanaman disesuaikan dengan arah mata angin terutama dilihat dari segi warna bunga atau buahnya (Tabel 2). Utara merupakana stana Dewa Wisnu dengan warna hitam, Timur Laut stana Dewa Sambu dengan warna biru, Timur stana Dewa Iswara dengan warna putih, Tenggara stana Dewa Mahesora dengan warna dadu, Selatan stana Dewa Brahma dengan warna merah, Barat Daya stana Dewa Rudra dengan warna oranye, Barat stana Dewa Mahadewa dengan warna kuning, dan Barat Laut stana Dewa Sangkara dengan warna hijau (Prajoko, 2012).

Tabel 2. Penempatan Tanaman Upakara Berdasarkan Warna Bunga dan Buahnya

\begin{tabular}{|c|c|c|c|}
\hline No & Penempatan & Arah & Nama Tanaman \\
\hline \multirow[t]{4}{*}{1} & $\overline{U M}$ & Utara & $\begin{array}{l}\text { Sirih, dadap, delem jawa, pandan wangi, kamajaya, } \\
\text { ratna, kenanga, telang biru, hortensia, pacar air } \\
\text { ungu, walisongo, seligi, sente, paku pipid, kumbang, } \\
\text { gelagah, simbar menjangan }\end{array}$ \\
\hline & & Timur & $\begin{array}{c}\text { Senduduk putih, nagasari, kacapiring, kamboja } \\
\text { putih, widuri putih, melati, nusa indah putih, selasih, } \\
\text { sudamala, wijaya kusuma }\end{array}$ \\
\hline & & Selatan & $\begin{array}{l}\text { Andong, bugenvil merah, kembang sepatu, soka } \\
\text { merah, mawar merah, kemukus }\end{array}$ \\
\hline & & Barat & $\begin{array}{l}\text { Gemitir, kembang merak kuning, pacar cina, } \\
\text { alamanda kuning, tebu, kapas }\end{array}$ \\
\hline
\end{tabular}




\begin{tabular}{|c|c|c|c|}
\hline No & Penempatan & Arah & Nama Tanaman \\
\hline \multirow[t]{4}{*}{2} & $\overline{M M}$ & Utara & $\begin{array}{l}\text { Salam, katuk, suji, daun wungu, uduh, brotowali, } \\
\text { bunut bulu, karuk, dlingo }\end{array}$ \\
\hline & & Timur & Cempaka putih, teratai putih, kelor \\
\hline & & Selatan & $\begin{array}{c}\text { Soko asti, delima merah, cabai, rambutan, buah } \\
\text { naga, kunyit, jahe, temu agung, temu gongseng, } \\
\text { temu tis }\end{array}$ \\
\hline & & Barat & $\begin{array}{l}\text { Puring, belimbing, jeruk, mangga, jambu biji, terong } \\
\text { bola }\end{array}$ \\
\hline 3 & NM & & $\begin{array}{c}\text { Beringin, pulai, pandan duri, buni, gegirang, } \\
\text { manggis, nyuh bulan, nyuh gading, mengkudu, } \\
\text { jambu air, leci, paku aji, waru }\end{array}$ \\
\hline
\end{tabular}

\subsubsection{Fungsi Tanaman Upakara dalam Arsitektur Lansekap}

Tanaman upakara yang digunakan sebagai elemen lunak taman pekarangan rumah di Kecamatan Payangan memiliki fungsi yang ganda yaitu sebagai tanaman upakara dan sebagai tanaman lansekap yang memiliki nilai estetika, bahkan beberapa tanaman juga memiliki khasiat sebagai obat. Masyarakat Kecamatan Payangan menganggap menggunakan tanaman yang memiliki fungsi ganda sebagai elemen lunak taman pekarangan rumah lebih menguntungkan. Tanaman upakara sebagai elemen lunak taman dapat dinikmati keindahannya dan ketika diperlukan utuk kelengkapan upakara akan lebih mudah untuk mencarinya. Tanaman memiliki fungsi yang beragam dalam lansekap, di antaranya yaitu kontrol pandangan, pembatas fisik, pengendali iklim, pencegah erosi, habitat satwa dan nilai estetika (Hakim dan Utomo, 2003). Berdasarkan hasil wawancara dapat diketahui bahwa tanaman upakara sebagai elemen lunak taman pekarangan rumah masyarakat difungsikan berbeda-beda di antaranya, sebagai pagar, peneduh dan keindahan.

Tabel 3. Fungsi Tanaman Upakara dalam Arsitektur Lansekap

\begin{tabular}{|c|c|c|}
\hline No & $\begin{array}{c}\text { Fungsi dalam } \\
\text { Arsitektur Lansekap }\end{array}$ & Jenis Tanaman \\
\hline 1 & Kontrol pandangan & $\begin{array}{l}\text { Delem jawa, salam, senduduk, nagasari, paku aji, pandan } \\
\text { wangi, gemitir, nusa indah, widuri, ratna, kenanga, selasih, } \\
\text { soka, sudamala, soko asti, pacar cina, hortensia, } \\
\text { alamanda, delima, jeruk, cabai, dan tebu }\end{array}$ \\
\hline 2 & Pembatas fisik & $\begin{array}{c}\text { Andong, katuk, suji, puring, pandan duri, seligi, daun } \\
\text { wungu, walisongo, uduh, gelagah, gegirang, kacapiring, } \\
\text { kamajaya, kembang sepatu, kembang merak, bugenvil dan } \\
\text { kapas }\end{array}$ \\
\hline 3 & Pengendali iklim mikro & Beringin, leci, cempaka, belimbing, buni dan manggis \\
\hline 4 & Pencegah erosi & Dadap, pulai, kelor, mengkudu, jambu air dan waru \\
\hline
\end{tabular}




\begin{tabular}{ccc}
\hline No & $\begin{array}{c}\text { Fungsi dalam } \\
\text { Arsitektur Lansekap }\end{array}$ & Jenis Tanaman \\
\hline 5 & Habitat satwa & Nyuh bulan, nyuh gading, mangga, jambu biji dan \\
rambutan \\
6 & Nilai estetika & $\begin{array}{c}\text { Sirih, kumbang, paku pipid, sente, simbar menjangan, } \\
\text { kemukus, brotowali, bunut bulu, karuk, kamboja, wijaya } \\
\text { kusuma, melati, telang, teratai, pacar air, mawar, terong } \\
\text { bola, buah naga, dlingo, jahe, kunyit, temu agung, temu } \\
\text { gongseng dan temu tis }\end{array}$ \\
\hline
\end{tabular}

\section{Simpulan dan Saran}

\subsection{Simpulan}

Berdasarkan uraian di atas dapat disimpulkan bahwa:

1. Tanaman upakara yang digunakan sebagai elemen lunak taman pekarangan rumah di Kecamatan Payangan adalah sebanyak 80 jenis. Sebanyak 24\% dari total tanaman ditanam di Utama Mandala, 63\% di Madya Mandala dan 13\% ditanam di Nista Mandala

2. Penempatan tanaman yang sesuai dengan filosofi Tri Mandala dan Asta Dala masih belum dilakukan karena kurangnya pengetahuan masyarakat tentang penempatan tanaman upakara sesuai filosofi tersebut.

3. Tanaman upakara yang digunakan sebagai elemen lunak taman pekarangan rumah di Kecamatan Payangan memiliki fungsi yang ganda yaitu sebagai tanaman upakara dan sebagai tanaman lansekap yang memiliki nilai estetika. Sebanyak 22 tanaman difungsikan sebagai kontrol pandangan, 17 tanaman sebagai pembatas fisik, enam tanaman sebagai pengendali iklim, enam tanaman sebagai pencegah erosi, lima tanaman sebagai habitat satwa dan 24 tanaman sebagai tanaman hias yang memiliki nilai estetika.

\subsection{Saran}

Berdasarkan simpulan di atas saran yang dapat diberikan yaitu :

1. Sebaiknya pemerintahan Kecamatan Payangan memberikan penyuluhan mengenai penempatan tanaman upakara sesuai filosofi budaya Bali agar masyarakat mengetahui lebih jelas tentang penempatannya fungsinya.

2. Sebaiknya dalam penempatan tanaman upakara berdasarkan filosofi Asta Dala dilakukan denagan mengkombinasikan warna tanaman pada setiap arah namun tetap memunculkan warna dominan sesuai filosofi Asta Dala.

\section{Daftar Pustaka}

Hakim, R. dan H. Utomo. 2003. Komponen Perancangan Arsitektur Lansekap: PrinsipUnsur dan Aplikasi. Bumi Aksara, Jakarta. 
Kountur, R. 2004. Metode Penelitian untuk Penulisan Skripsi dan Tesis. Penerbit PPM. Jakarta

Prajoko, A. 2012. "Pertamanan Tradisional Bali Berlandaskan Unsur Satyam, Siwam, Sundaram Religi dan Usada" Tersedian online:http://www.parissweethome. com/bali/cultural_my.php?id=11. (Diakses 26 Desember 2015).

Putra, Miarta I.N. 2009. Mitos-Mitos Tanaman Upakara. Pustaka Manikgeni. Denpasar

Sardiana, I. K., N. M. Wiasti, I.N. Wardi. 2012. Etnobotani Bali. Udayana University Press

Srimad, S. 2006. Bhagavad-gita Menurut Aslinya. Hanuman Sakti

Ulwan, M. N. 2014. "Teknik pengambilan sampel dengan metode purposive sampling" Tersedia online: http://www.portal-statistik. com/2014/02/teknik-pengambilan-sampeldengan-metode.html. (Diakses 7 Januari 2016) 